\title{
A CLINICAL CASE OF PARESTHESIA DUE TO AMALGAM RETROGRADE FILLING DISSEMINATED IN THE UPPER JAW AND SOFT TISSUES
}

\author{
Georgiev T. ${ }^{1}$, S. Peev $^{3}$, G. Papanchev ${ }^{1}$, Ts. Borisova-Papancheva ${ }^{2}$, E. Aleksieva ${ }^{1}$ \\ ${ }^{1}$ Department of Oral and Maxillofacial Surgery, ${ }^{2}$ Department of Conservative Dental Medicine and \\ Pediatric Dental Medicine, Faculty of Dental Medicine, Medical University of Varna, \\ ${ }^{3}$ Department of Parodontology, Faculty of Dental Medicine, Medical University of Plovdiv
}

\begin{abstract}
Periradicular interventions are among the most common in endodontic surgery. In cases where the apical third of the root canal can not be cleaned and filled in advance by the conventional anterograde method, the apical resection is finished by cavity preparation and retrograde filling placement. Amalgam usage as a retrograde filler results in many complications. The present article reports a similar clinical case. The disadvantages of amalgam were discussed. The new materials designed for root canal treatment should meet numerous requirements. Usage of new methods and materials could eliminate the need of apicoectomy and retrograde filling.
\end{abstract}

Key words: apical resection, amalgam retrograde filling, surgical treatment, periradicular surgery, apicoectomy

\section{INTRODUCTION}

The failure to conduct adequate endodontic treatment because of curves and/or inaccessible root canals of the teeth is associated with the extraction of these teeth or with the need for apicoectomy. In some cases it is necessary to do a retrograde filling. They are routine manipulations when carried out by an experienced specialist, who has the necessary equipment and analysis. In the past, amalgam was the most often used material for retrograde filling. Nowadays it is not used frequently because of a number of negative properties.

\section{CASE REPORT}

A clinical case of a 38-year old patient was reported. He was forwarded to the Department of Oral and Maxillofacial Surgery, Faculty of Dental Medicine, Medical University of Varna, by a general practitioner. The clinical examinations established a missing tooth 25 . From the medical history it became clear that the same tooth had already undergone a repeatedly endodontic treatment. However, it necessitated a surgical intervention consisting in apicoectomy because of the lack of conservative influence on the periradicular changes. The apical resection

Address for correspondence

T. Georgiev, Dept. of Oral and Maxillofacial Surgery, Faculty of Dental Medicine, Medical University of Varna

150, Tzar Osvoboditel Blvd, Varna 9002

e-mail: tgeorgievphd@yahoo.com was followed by an amalgam retrograde filling. Eight months later the process exacerbated again and that was why a tooth extraction and a flapless curettage through the extraction wound should be performed. Since then, the patient reported periodic numbness and tingling in the

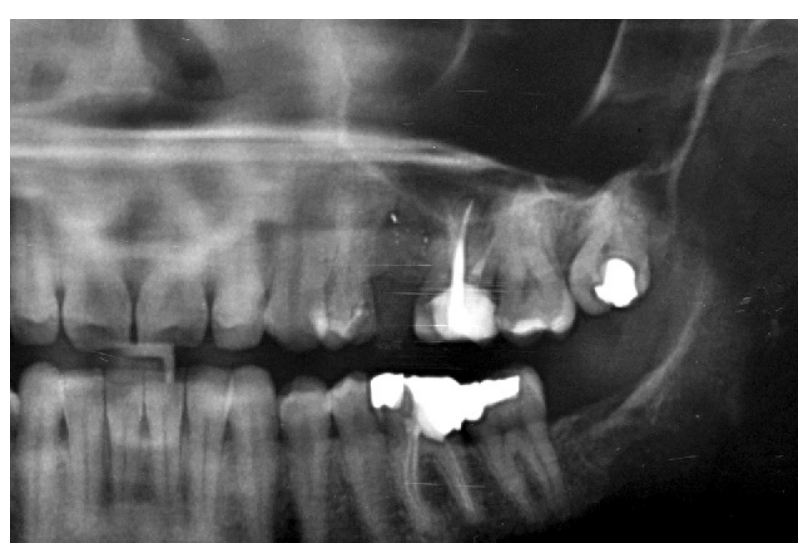

Fig. 1. Initial panoramic x-ray image

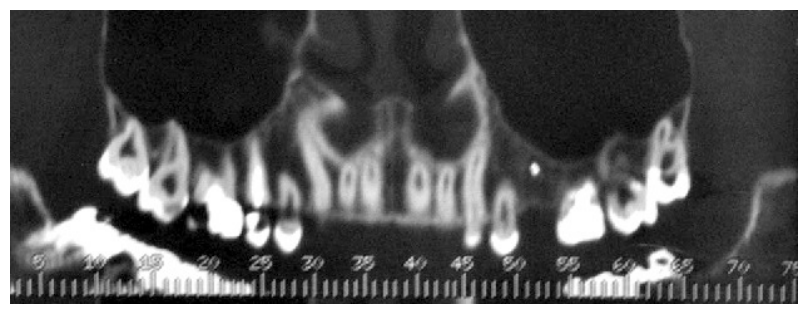

Fig. 2. CT of the upper jaw 


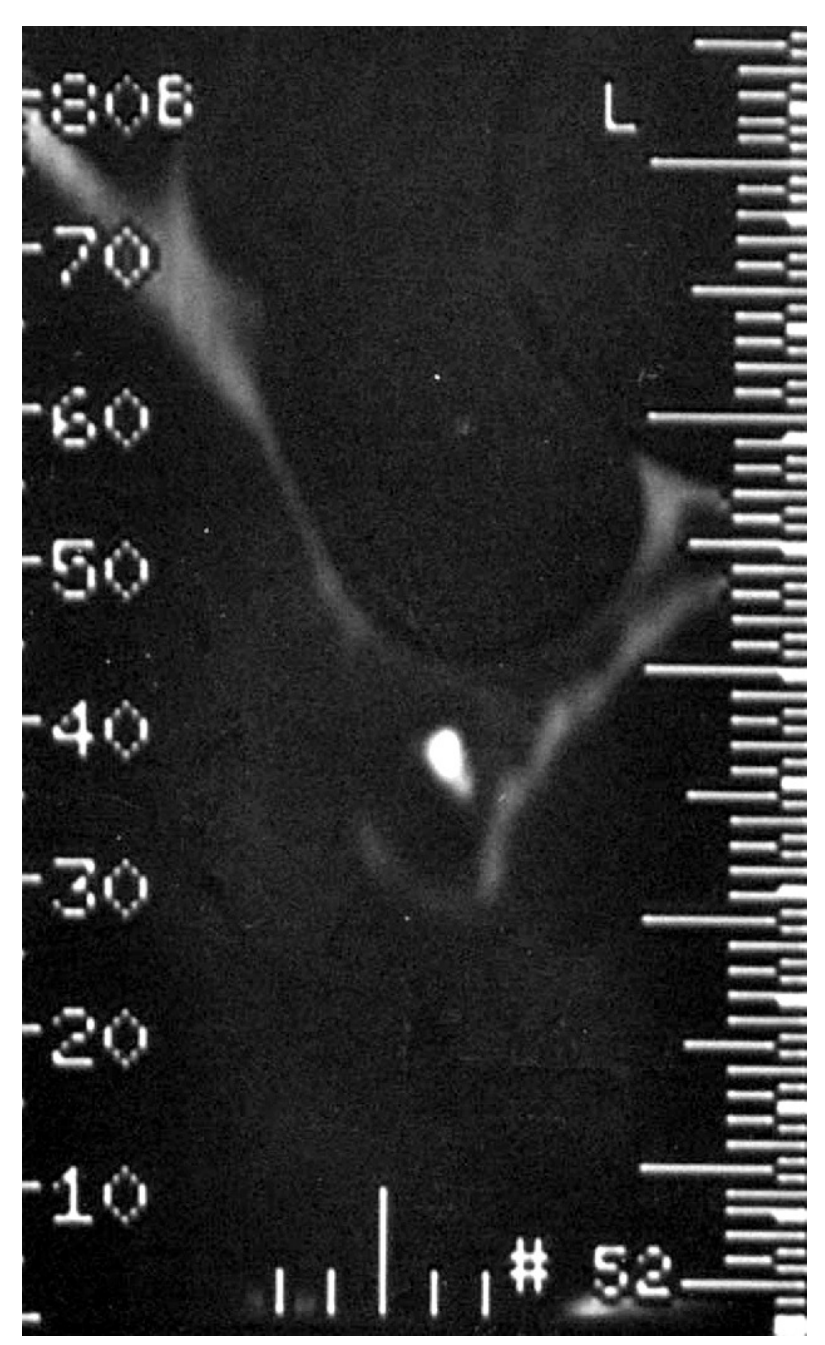

Fig. 3. CT of the upper jaw

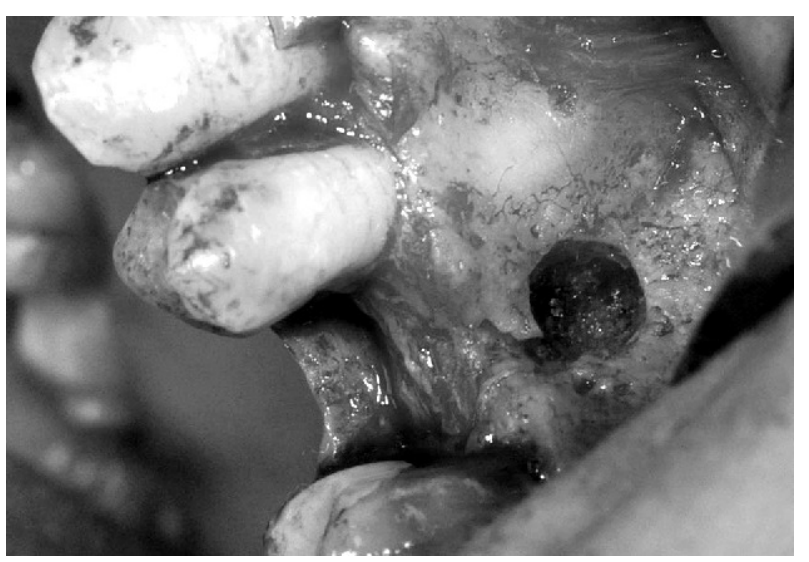

Fig. 4. A mucoperiosteal flap with amalgam parts

gingiva and mucosa overlying the missing tooth Symptoms of varying strength and intensity occurred in a few weeks and persisted for several days. They were spontaneous and not influenced by anything. We administered a panoramic x-ray (Fig. 1) and a computed tomography (CT) of the upper jaw (Fig. 2 and Fig. 3). A number of strong shades with metal thickness sized from 0,5 to $2,00 \mathrm{~mm}$ in diameter and irregularly scattered in the

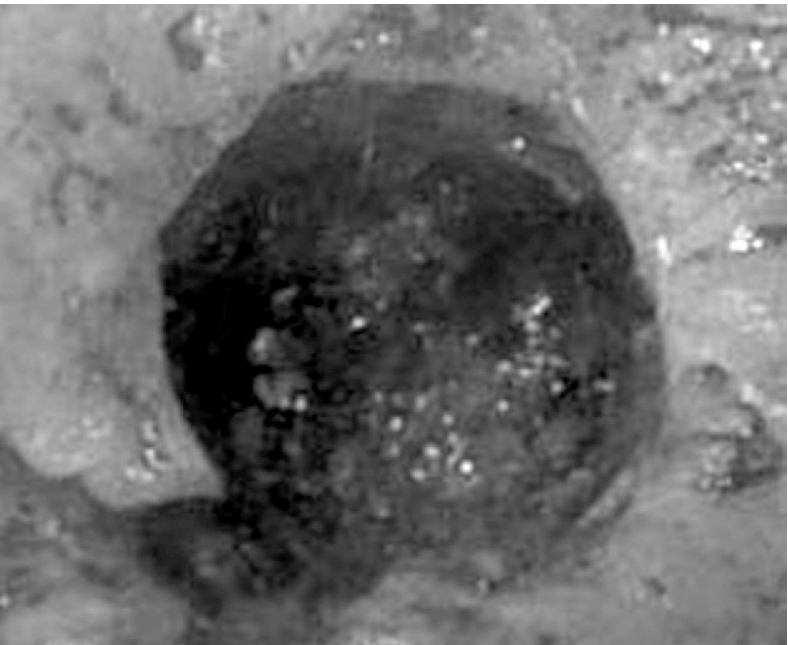

Fig. 5. Amalgam parts

bone on the place of the missing tooth 25 were detected. Based on the medical history, clinical and paraclinical findings we concluded that it concerned a number of foreign bodies from amalgam disseminated in the bone and the soft tissues as a result of improper handling during the apical osteotomy and extraction. They caused, most likely, patient's complaints. We decided to remove the amalgam

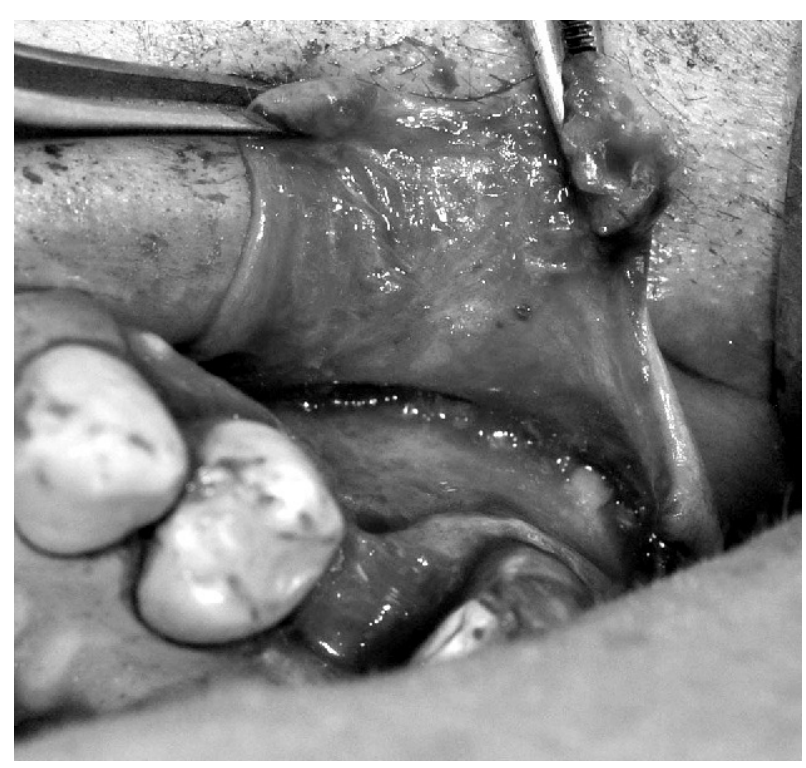

Fig. 6. Amalgam pieces in the periosteum

inclusions, to reconstruct the section of the maxillary alveolar ridge and to put an implant during the same surgical intervention. The patient was aware of the treatment plan and accepted it. Routine blood tests showed no abnormalities.

The operation was carried out under local infiltration anesthesia with $4 \mathrm{~mL}$ of $4 \%$ Ubistesin. A triangular mucoperiosteal flap with a horizontal incision running along the crest of the alveolar ridge in the area of the missing tooth 25 and a vertical incision starting from the vestibule up to tooth 23 was raised. We determined the place of 


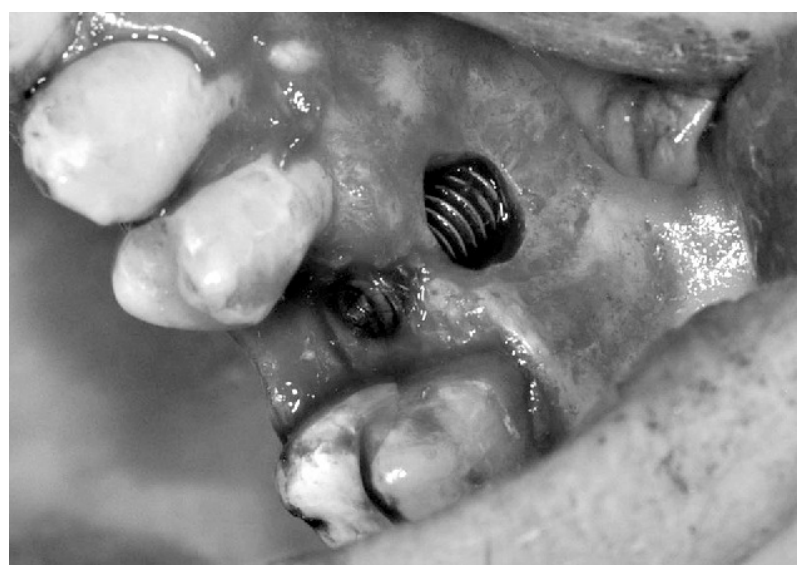

Fig. 7. A reconstruction with a Straumann bone level implant

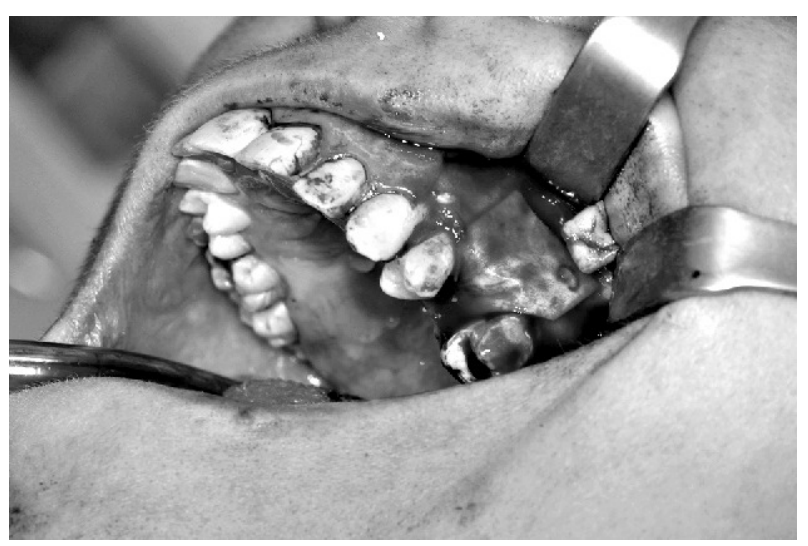

Fig. 9. Jason membrane positioned over the bone grafting material

the amalgam bone build-ups using a periodontal probe and CT scans. The osteotomy was carried out with a round bur. A large amalgam part sized $2 \mathrm{~mm}$ (Fig. 4 and Fig. 5) and a few small particles were reached and removed. A careful hemostasis and irrigation were done and no any other particles were detected. During the inspection of the soft tissues many amalgam pieces of a diameter of $0,5 \mathrm{~mm}$ were found out in the periosteum (Fig. 6) being visible on the panoramic x-ray, too. We carefully removed them. For the reconstruction a Straumann bone level implant of 4,1/10 mm was chosen (Fig. 7). The osteotomy was carried out according to the surgical protocol. The implant was inserted into the bone as the lower third fell into the defect created by the previously removed foreign bodies. We used $1,0 \mathrm{~mL}$ of Cerabone (bovine bone grafting material) (Fig. 8) and Jason membrane of 15/20 mm (pericardium membrane) (Fig. 9) for the augmentation (guided bone regeneration) in that area. The mucoperiosteal flap was mobilized and sutured with Dafilon 5/0 (a non-absorbable synthetic monofilament suture). Proper drugs were prescribed to the patient. The healing period ran smoothly. A panoramic x-ray taken after three months showed a good periimplant state. The implant was uncovered three months later and a healing abutment was placed for 4 weeks. After this period, there was a very well-developed sulcus. The defect was restored with a

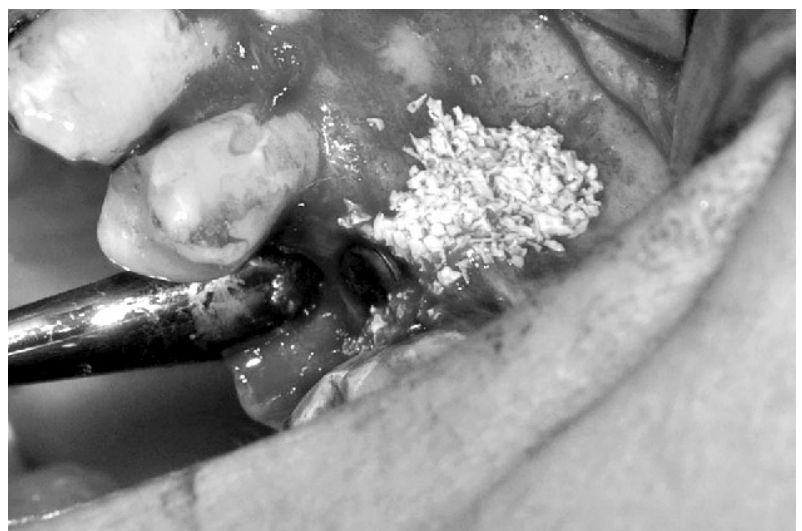

Fig. 8. Bone grafting with 1,0 $\mathrm{mL}$ of Cerabone

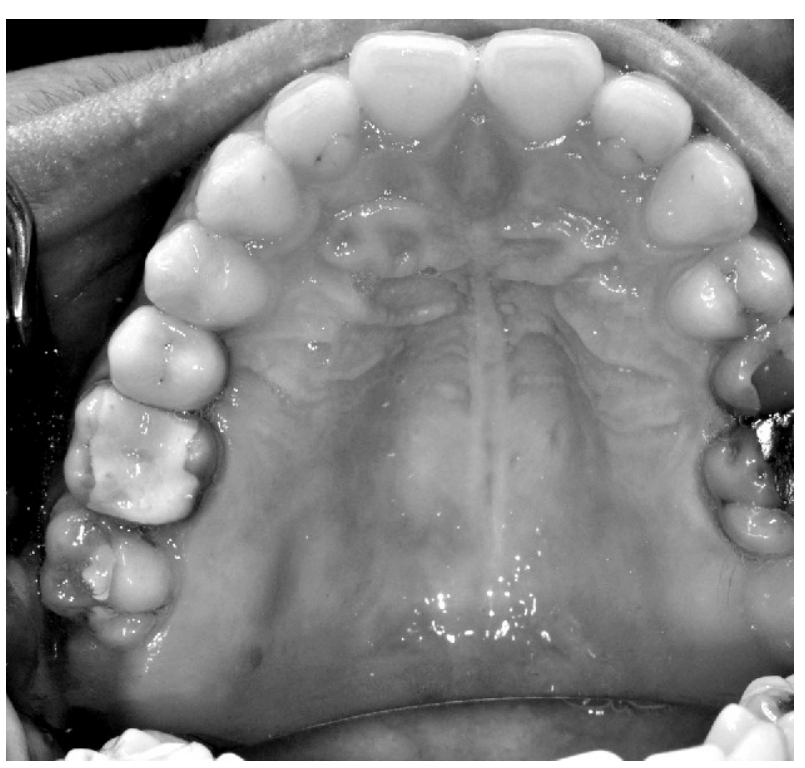

Fig. 10. Final appearance of the upper jaw

metal-ceramic crown according to the prosthetic protocol (Fig. 10). Three weeks later, the patient felt much better. The periimplant soft tissues were satisfactory. The patient shared that no postoperative complaints of burning, numbness and tingling had appeared anymore.

\section{DISCUSSION}

Periradicular interventions are among the most common in endodontic surgery. Their main purposes are to eliminate the cause of infection and create a favourable environment for the healing process. In cases where the apical third of the root canal can not be cleaned and filled in advance by the conventional anterograde method, the apical resection is finished by cavity preparation and retrograde filling placement. These manipulations are routine when carried out by an experienced specialist with the necessary equipment and analysis. The purpose of the retrograde filling is to put a barrier between the root-canal system and the periradicular tissues, thus limiting the possibility of invasion of bacteria and their products in the soft tissues. 
Up-to-now, many different materials have been used for this purpose. Usage of such a material with this purpose should to meet the following requirements $(2,8)$ :

1. to 'seal' the root end three-dimensionally and prevent the release of microorganisms and their products in the periradicular tissues;

2. to be non-toxic;

3. to be non-carcinogenic;

4. to be biocompatible;

5. to be not soluble in tissue fluids;

6. to be dimensionally stable;

7. to be unaffected by moisture in either the set, or unset state;

8. to be easy to handle;

9. to be easily distinguishable on radiographs;

10. not to stain the periradicular tissues and the tooth;

11. not to corrode or to be electrochemically active, and

12. to be bioinductive.

Every specialist must be aware of these requirements and bear them in mind when starting the apicoectomy and retrograde filling. Traditionally, the amalgam was the material of choice in the cases of retrograde filling. This was due to the fact that it was widely used and most dentists thought that they were well-acquainted with its qualities. Indeed, it is cheap, easy to handle, easily distinguishable on radiographs and gives acceptable results in some cases. However, its use is related with a lot of disadvantages:

1. Corrosion and dimensional changes

Amalgam corrodes at different rates depending on its composition. Electrochemical amalgam corrosion was reported to be responsible for failures of amalgam root-end fillings $(2,7,16)$;

2. Amalgam tattoos

Small amalgam particles' scattering during root-end filling placement can lead to tissue disfigurement. When they accumulate in one place and then corrode this results in 'focal argyria' (a condition characterized by blue or gray-blue staining of the soft tissues) $(2,9)$;

3. Amalgam biocompatibility

It is a matter of unequivocal opinion, however, many in vitro and in vivo studies in animals have reported cytotoxicity of amalgam and inflammatory response of the soft tissue (3). It is considered that its cytotoxicity and the reactions that it induces vary depending on its composition. Zinc-containing amalgams are more cytotoxic than those which do not contain it $(2,5,10,12,14,15,20)$;

4. The amalgam does not seal the root end three-dimensionally and thus does not prevent the leakage of microorganisms and their products in the periradicular tissues $(2,13)$;

5. Numerous surveys based on clinical studies have reported poor outcomes with amalgam used as a root-end filling material $(2,4,6)$.

All these negative properties of the amalgam in combination with the wrong surgical protocol of apical resection and tooth extraction along with the lack of clinical exami- nations explain patient's complaints as presented in our case report.

\section{CONCLUSION}

Nowadays endodontics and any other dental branches evolve very rapidly. The new methods and materials designed for root canal treatment as good as eliminate the need of apicoectomy and retrograde filling. However, when necessary, it must be done by a specialist with the necessary equipment and analysis. Because of all the disadvantages of the amalgam and the availability of newer and better materials for retrograde filling like glass ionomer cements, MTA (Mineral Trioxide Aggregate) etc. this material has gone down in history $(1,2,17-19)$.

\section{REFERENCES}

1. Bates, C. F., D. L. Carnes, C. E. del Rio. Longitudinal sealing ability of mineral trioxide aggregate as a root-end filling material.- J. Endod., 22, 1996, No 11, 575-578.

2. Chong, B. S., T. R. Pitt Ford. Root-end filling materials: rationale and tissue response.- Endod. Topics, 11, 2005, 114-130.

3. Cox, S. W., B. M. Eley. Further investigations of the soft tissue reaction to the gamma 1 phase $(\mathrm{Ag} 2 \mathrm{Hg} 3)$ of dental amalgam, including measurements of mercury release and redistribution.Biomaterials, 8, 1987, No 4, 296-300.

4. Dorn, S. O., A. H. Gartner. Retrograde filling materials: a retrospective success-failure study of amalgam, EBA, and IRM.- Endodontics, 16, 1990, No 8, 391-393.

5. Fardal, O., A. C. Johannessen, T. Morken. Gingivo-mucosal and cutaneous reactions to amalgam fillings.- J. Clin. Periodontol., 32, 2005, No 4, 430-433.

6. Frank, A. L., D. H. Glick, S. S. Patterson, F. S. Weine. Long-term evaluation of surgically placed amalgam fillings.- J. Endod., 18, 1992, No 8, 91-398.

7. Hohenfeldt, P. R., J. A. Aurelio, H. Gerstein. Electrochemical corrosion in the failure of apical amalgam. Report of two cases.- Oral Surg. Oral Med. Oral Pathol., 60, 1985, No 6, 658-660.

8. Ingle, J. I., L. K. Bakland, J. C. Baumgartner. In: Ingle's Endodontics. 6. ed. Hamilton, BC Decker Inc, 2008, 1233-1294.

9. Kauzman, A., M. Pavone, N. Blanas, G. Bradley. Pigmented lesions of the oral cavity: review, differential diagnosis, and case presentations.J. Can. Dent. Assoc., 70, 2004, No 10, 682-683.

10. Makkawy, H. A., S. Koka, M. T. Lavin, N O. Ewoldsen. Cytotoxicity of root perforation repair materials.- J. Endod., 24, 1998, No 7, 477-479.

11. McCullough, M. J., M. J. Tyas. Local adverse effects of amalgam restorations.- Int. Dent. J., 58, 2008, No 1, 3-9. 
12. Parizi J. L., G. A. Nai. Amalgam tattoo: a cause of sinusitis?- J. Appl. Oral Sci., 18, 2010, No 1, 100-104.

13. Pereira, C. L. M. S. Cenci, F. F. Demarco. Sealing ability of MTA, Super EBA, Vitremer and amalgam as root-end filling materials.- Braz. Oral Res., 18, 2004, No 4, 317-321.

14. Pitt Ford, T. R., J. O. Andreasen, S. O. Dorn, S. P. Kariyawasam. Effect of IRM root end fillings on healing after replantation.- J Endod., 20, 1994, No 8, 381-385.

15. Pitt Ford, T. R., J. O. Andreasen, S. O. Dorn, S. P. Kariyawasam. Effect of super-EBA as a root-end filling on healing after replantation.- $J$. Endod., 21, 1995, No 1, 13-15.

16. Pleva, J. Corrosion and mercury release from dental amalgam.- J. Orthomol. Med., 4, 1989, No 3.

17. Torabinejad, M., R. K. Higa, D. J. McKendry, T. R. Pitt Ford. Dye leakage of four root-end filling materials: effects of blood contamination.- J. Endod., 20, 1994, No 4, 159-163.

18. Torabinejad, M., C. U. Hong, F. McDonald, T. R. Pitt Ford. Physical and chemical properties of a new root-end filling material.- J. Endod., 21, 1995, No 7, 349-353.

19. Torabinejad, M., P. V. Smith, J. D. Kettering, T. R. Pitt Ford. Comparative investigation of marginal adaptation of mineral trioxide aggregate and other commonly used root-end filling materials.- J. Endod., 21, 1995, No 6, 295-299.

20. Zhu, Q., K. E. Safavi, L. S. Spangberg. Cytotoxic evaluation of root-end filling materials in cultures of human osteoblast-like cells and periodontal ligament cells.- Endodontics, 25, 1999, No 6, 410-412. 